\title{
INFLUENCE OF WORK AND TOOL MATERIALS ON PARAMETERS OF ELECTRICAL DISCHARGE MACHINING (EDM)
}

\author{
A.K.M.N. Amin* and A.K. Sarder** \\ *Department of Mechanical Engineering, International Islamic University Malaysia \\ **Department of Industrial and Production Engineering, Bangladesh University of Engineering and \\ Technology, Dhaka-1000, Bangladesh, \\ email:akamin@iiu.edu.my
}

\begin{abstract}
Influence of the properties of work and tool materials on material removal rate (MRR), tool wear ratio (TWR), thickness of the recast layer, surface roughness and accuracy of machining in EDM process has been investigated. Copper brass, stainless steel, mild steel and grey cast irou have been used in various combinations as work and tool materials. From the experimental results it is found that MRR slows down with machining time. Apart from that it has been found that MRR and TWR are inversely proportional to the melting points of the work and tool materials respectively. Electrical conductivity of the tool material also has appreciable influence on tool wear ratio. Wear ratio was found to be minimum in the case of the copper electrode having maximum electrical conductivity. It has been also observed that for all combinations of work and tool materials, a recast layer is formed on the machined surface. It has been observed that the micro cavities formed in the cases of lower melting point electrode materials like copper and brass having higher electrical conductivity are comparatively smaller in size (2-3 $\mu \mathrm{m})$ as compared to the sizes of the micro cavities $(8-20 \mu \mathrm{m})$ formed in the cases of high melting pointer electrodes having also lower electrical conductivity. Consequenty the machined surface roughness produced in the latter cases is higher. It has been also observed that the debris concentration increases due to side sparking of the electrode. The tendency of debris concentration is the maximum at the middle of the tooljob interface resulting in high bottom surface inaccuracy, specially when high melting point work materials are machined with electrodes like brass having low melting point and relatively lower electrical conductivity. From the point of view of MRR, brass electrodes have been found to be the most suitable tool, but from the point of view of machining accuracy and surface finish copper electrodes were found to yield the best result for the given set of job materials. So it was concluded that brass electrodes should be recommended for rough machining and copper electrodes for finish machining of the given work materials.
\end{abstract}

\section{INTRODUCTION}

With the advancement of science and technology new materials and alloys with high mechanical properties are emerging for applications in various sectors of the industry. The new materials are known for their poor machinability and require special techniques for machining. Electrical discharge machining (EDM) is one of the earliest non-traditional manufacturing processes successfully employed for machining of most of these materials. The process is mainly applied for final machining of die surfaces. The materials of dies for various applications are stainless steel or various grades of alloy steels. Effective application of the EDM process for machining of these materials depends on correct choice of the job-electrode materials combination and proper selection of current and voltage parameters. Right selection would lead to higher material removal rate, accuracy, surface roughness and surface integrity of the work piece. The main objective of the work was to determine the appropriate tool materials for machining various work materials on the basis of material removal rate, tool wear, machining accuracy, job surface roughness and thickness of the recast layer.

\section{EXPERIMENTAL PROCEDURE}

Experiments were conducted on Electrical Discharge machine, Model No-18401, employing pulse generator and electromechanical type servo motor for spark gap control (Figure 1). Brass, copper, mild steel, stainless steel and cast iron were used as electrode as well as work piece materials in various combinations during the experiments. Machining was performed at right angle to the job surface. Kerosene was used as the dielectric fluid. Depth of the cavity machined was measured using a dial gauge having micrometer scale readings and tool wear was measured using an instrument microscope after a fixed interval of machining. From these data the material removal rate (MRR) and the wear ratio (W.R) were calculated. Calculation of Material Removal Rate was based on the measurement of volume loss of work material per minute of machining time. The thickness of the Recast layer (RL) was measured on a metallographic microscope. The wear ratio of the electrode is defined as the percentage of volume of electrode wear per unit volume of material removal in the same machining interval. The average surface roughness of the machined surface was measured on a surface roughness measuring instrument model Sulftest AB.5. 


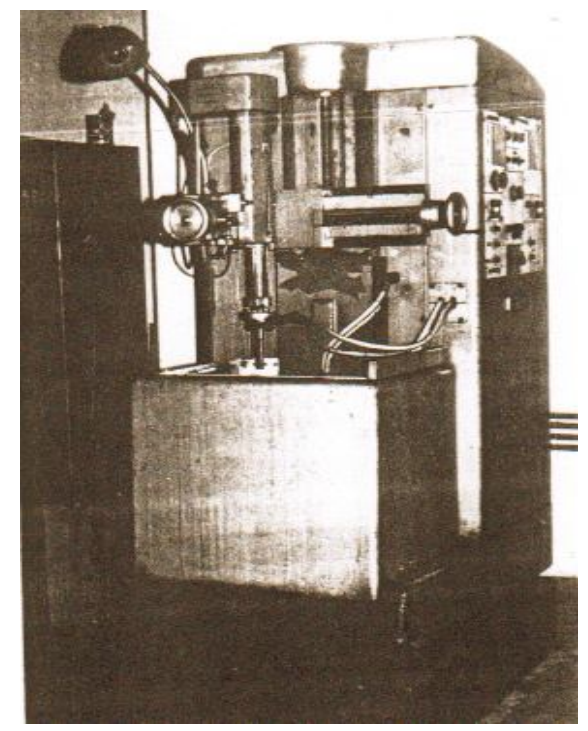

Figure 1: Electrical Discharge machine, Model No18401

\subsection{Condition and Assumption of the experiment}

From the earlier theoretical investigations it was observed that tool wear ratio, material removal rate and job surface roughness depend on electrical conductivity and melting points of the work and tool materials, current polarity, gap between the electrode and the work piece, etc. Influence of the magnetic properties on the tool wear was neglected throughout the investigation. Influence of dielectric flow on material removal rate was eliminated by employing only immersion type fluid flow. Following assumptions were made during the study:

(a) Temperature and pressure of dielectric fluid were constant.

(b) Formation of the recast layer on the machining surface occured at steady state condition.

(c) Current consumption was constant throughout the whole study.

(d) Particles were eroded uniformly from the electrode.

\section{Machining Conditions}

Feed rate (f): $\quad 0-1 \mathrm{~mm} / \mathrm{min}$ (Servo control)

Gap voltage (v): 2- $3 \mathrm{~V}$.

Peak current (i) :0.4-0.5 A

Total Machining Time (t): 225 mins.

\section{EXPERIMENTAL RESULTS}

\subsection{Material Removal Rate (MRR)}

Curves of Cumulative Material Removal versus machining time were plotted for various combinations of job and tool materials. From these curves the Rate of Metal Removal were calculated and bar charts are plotted (Fig.1). It may be observed from Fig. 1 that the MRR for brass, copper and mild steel is the highest for brass tool; whereas in the cases of stainless steel and cast iron, copper and cast iron tools respectively show the highest metal removal rate. The job materials may be placed in the descending order of their average MRR as follows: brass, cast iron, copper, mild steel and stainless steel. It may be observed from Figure 1 and Table1 that the average MRR for brass having the lowest melting point is the higest. The average MRR for cast iron and copper having relatively lower melting points are also relatively higher. At the same time the average values of MRR for mild steel and stainless steel having higher melting points are relatively lower. This may be associated with lower energy requirement for material removal during EDM bombardment in the cases of lower melting point materials.

\subsection{Tool Wear Ratio}

The tool wear ratio is defined as the ratio of the volume of electrode wear to the volume of work material removed. The relationship of tool wear ratio for the given job material and tool material combination is shown in Figure 2. Minimum wear ratio is observed in the case of copper electrode, while the maximum ratio is obserded in the case of brass electrode for all the combinations of tool and work materials. Copper electrodes show lower wear ratio than other electrodes due to their higher electrical conductivity and consequently more efficient

Table 1: Melting Points of the Job/Tool Materials.

\begin{tabular}{|l|l|l|}
\hline Number & Job/Tool Material & $\begin{array}{l}\text { Melting } \\
\text { (Approximate), }{ }^{0} \mathrm{C}\end{array}$ \\
\hline 1 & Brass & 1000 \\
\hline 2 & Copper & 1085 \\
\hline 3 & Cast Iron & 1200 \\
\hline 4 & Stainless Steel & 1420 \\
\hline 5 & Mild Steel & 1500 \\
\hline
\end{tabular}




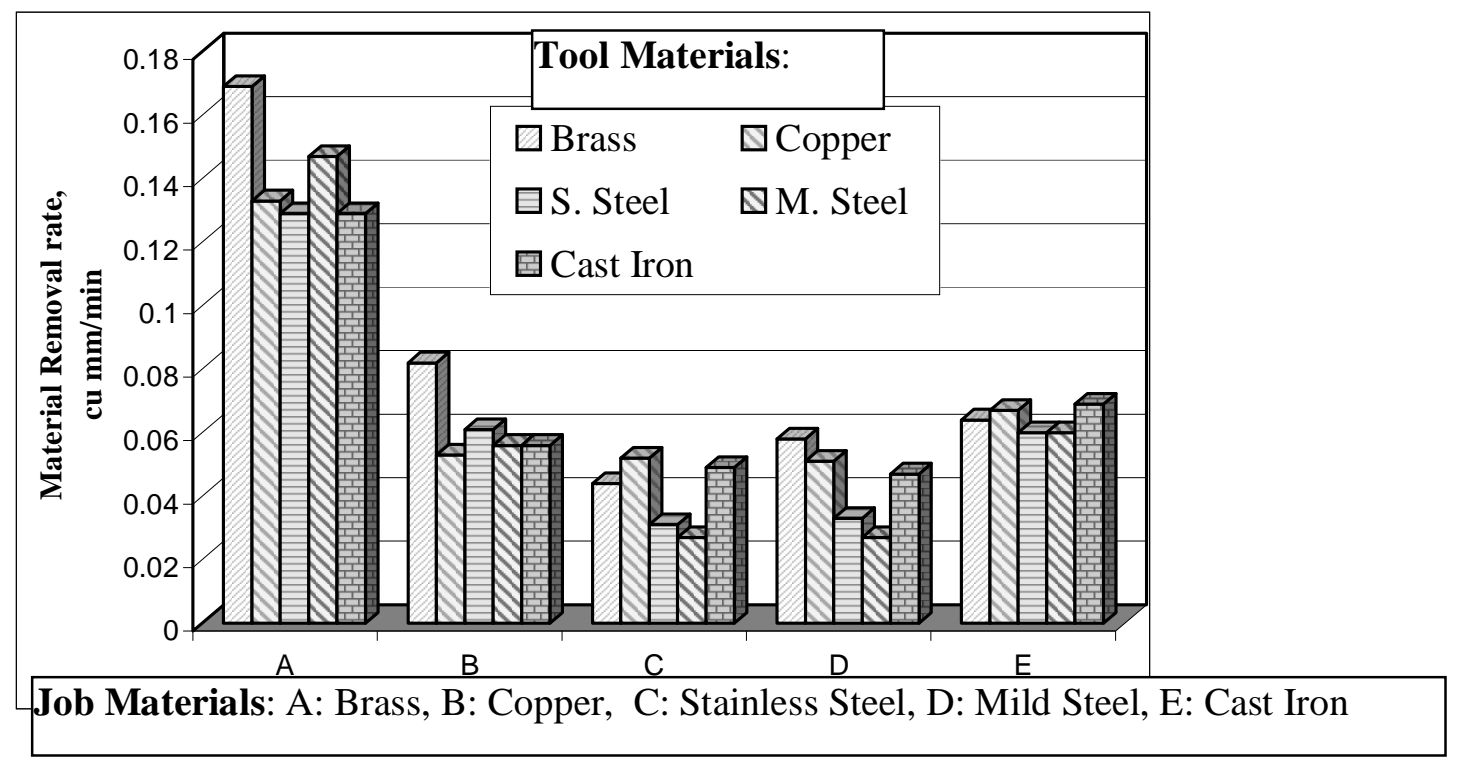

Fig. 1: Material Removal Rate for different combinations of Job Materials (A, B, C, D, E) and Tool materials

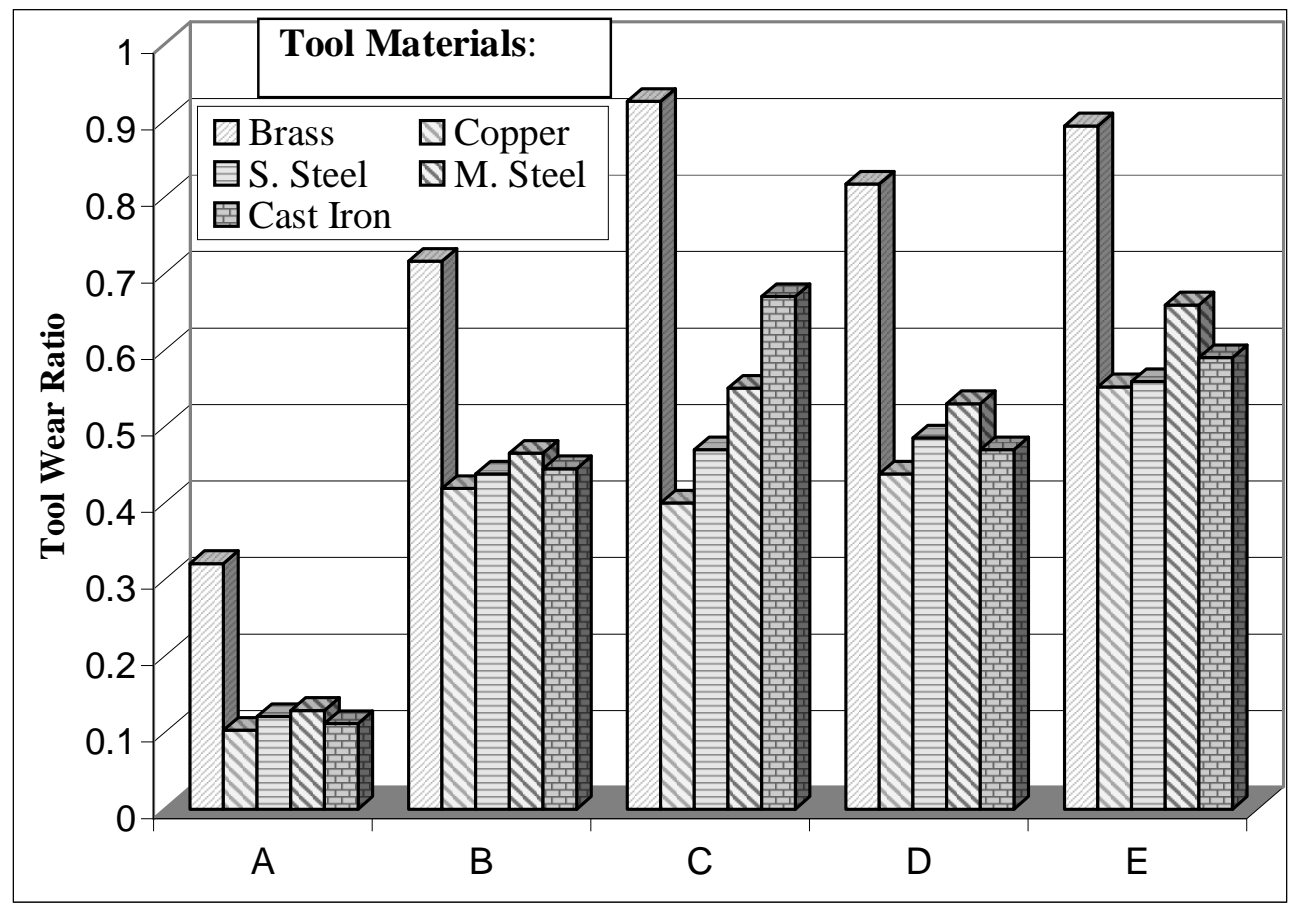

Job Materials: A: Brass, B: Copper, C: Stainless Steel, D: Mild Steel, E: Cast Iron

Fig. 2: Tool Wear Ratio for different combinations of Job Materials (A, B, C, D, E) and Tool materials.

bombardment on the work material surface by electrons during the EDM process. Higher wear ratio of brass electrodes is associated with the lower melting point of brass. The electrode particles eroding at a lower temperature require less energy. Figure 2 also shows that the ratio is less than one or in other words the MRR is higher than the wear rate of the electrodes. This is associated with the direct polarity used in the process, in which the tool acts as the cathode, causing bombardment of the anode (work piece) by electrons. Since the bombardment caused by the electrons has higher energy than the bombardment caused later by 
ions and particle from the vaporized anode (job materials), the MRR is higher than that of tool wear.

\subsection{Recast Layer (RCL)}

Metallographic specimens of the middle section of the machined specimens were prepared. A sample of the micro-photographs showing the recast layer is illustrated in Figure 3.

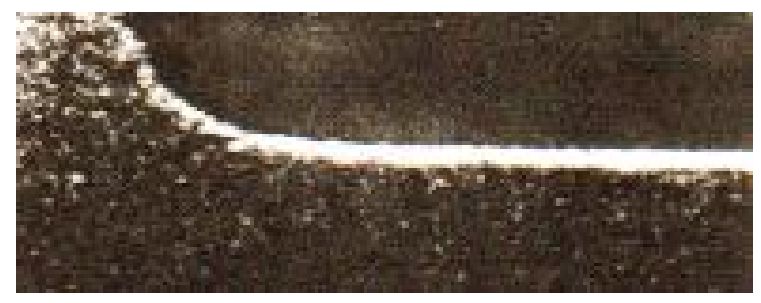

Fig. 3: Recast Layer. Job Material: Mild Steel, Tool Material: Stainless Steel.

Thicknesses of the recast layers on the machied surface for different combinations of the tool and work piece materials are represented in Figure 4. This layer is also termed as the white layer due to its appearance since it is unetchable and can be easily identified. The repetitive sparks release energy in the form of local bombardment. As a result local temperature reach an extremely high value at the spot of electrical discharge causing the metal particles to melt and vaporize. These particles are subsequently flushed away by dielectric medium. Some droplets of the particles are trapped and then solidified on to the previously eroded surface to form a RCL. This layer is chromatically different from the original surface when observed with polarized light and viewed under the microscope. Since the electrode is fed vertically from the top into the work piece it prevents the dielectric from effective flushing of the particles at the bottom of an EDM hole. As a result these particles are deposited on to the surface ensuring the rei ${ }^{-\ldots \ldots \ldots}$ of the recast layer. Figure 4 shows that in $2 \mu \mathrm{m}$ he brass electrodes form a RCL of higher umumess than other electrodes. It may be explaind by the fact that the particles which are eroded from brass electrode having higher density of heat are able to penetrate to higher thickness of job materials. Any molten metal which is not expelled during the process is resolidified to form a hard skin on the surface. Thermal stress, plastic deformation and shrinkage result in residual tensile stresses. Directly beneath the hand skin is a heat affected

zone, which is the case with the heat treated materials. This layer is softer than the parent metal due to a loss of hardness of the hardened metal. On the contrary the hardness of the recast layer is higher than the base material hardness, which leads to longer life of the product. This layer has also higher lubricant retaining properties as are desirable for dies ${ }^{[4]}$.

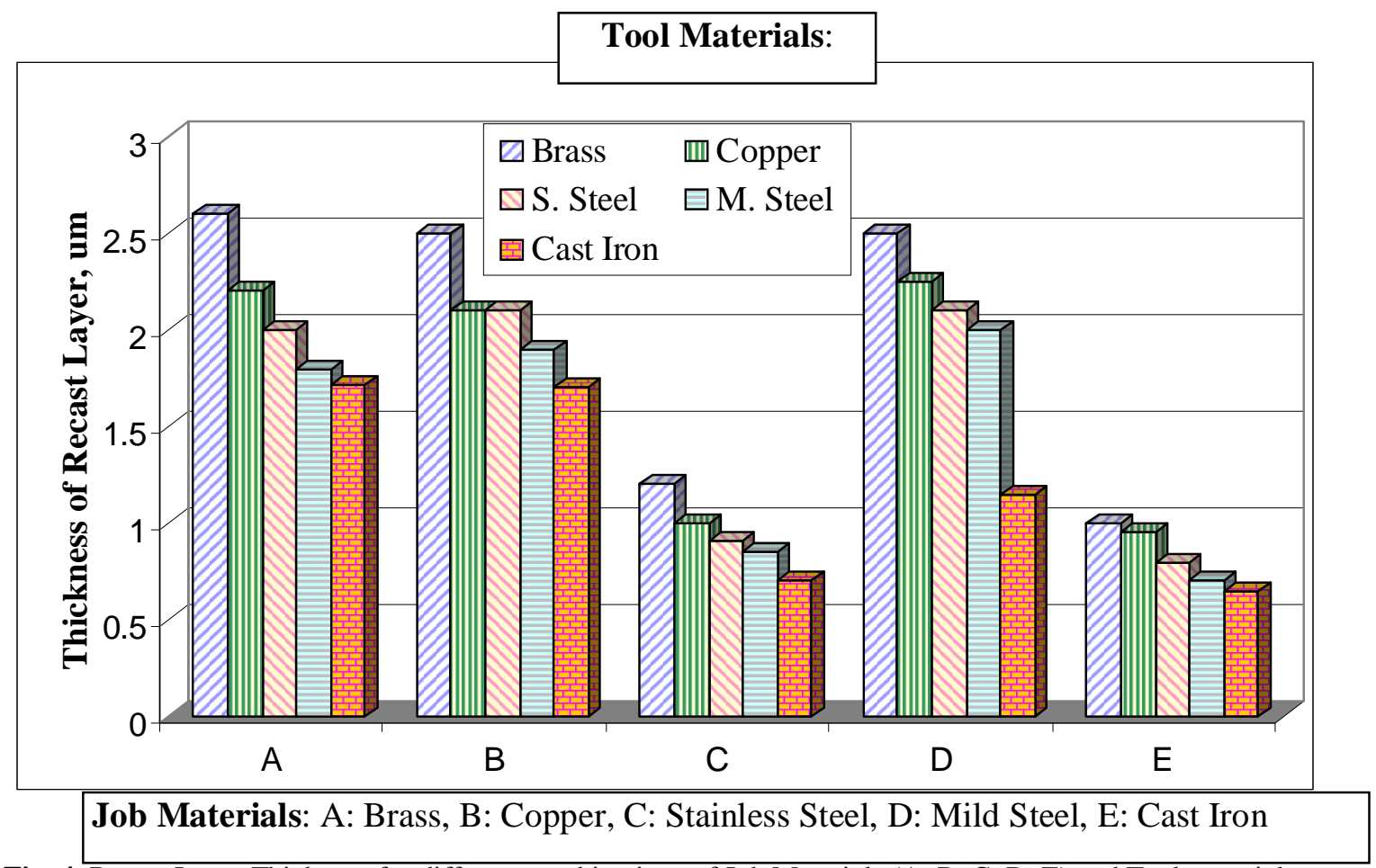

Fig. 4: Recast Layer Thickness for different combinations of Job Materials (A, B, C, D, E) and Tool materials. 


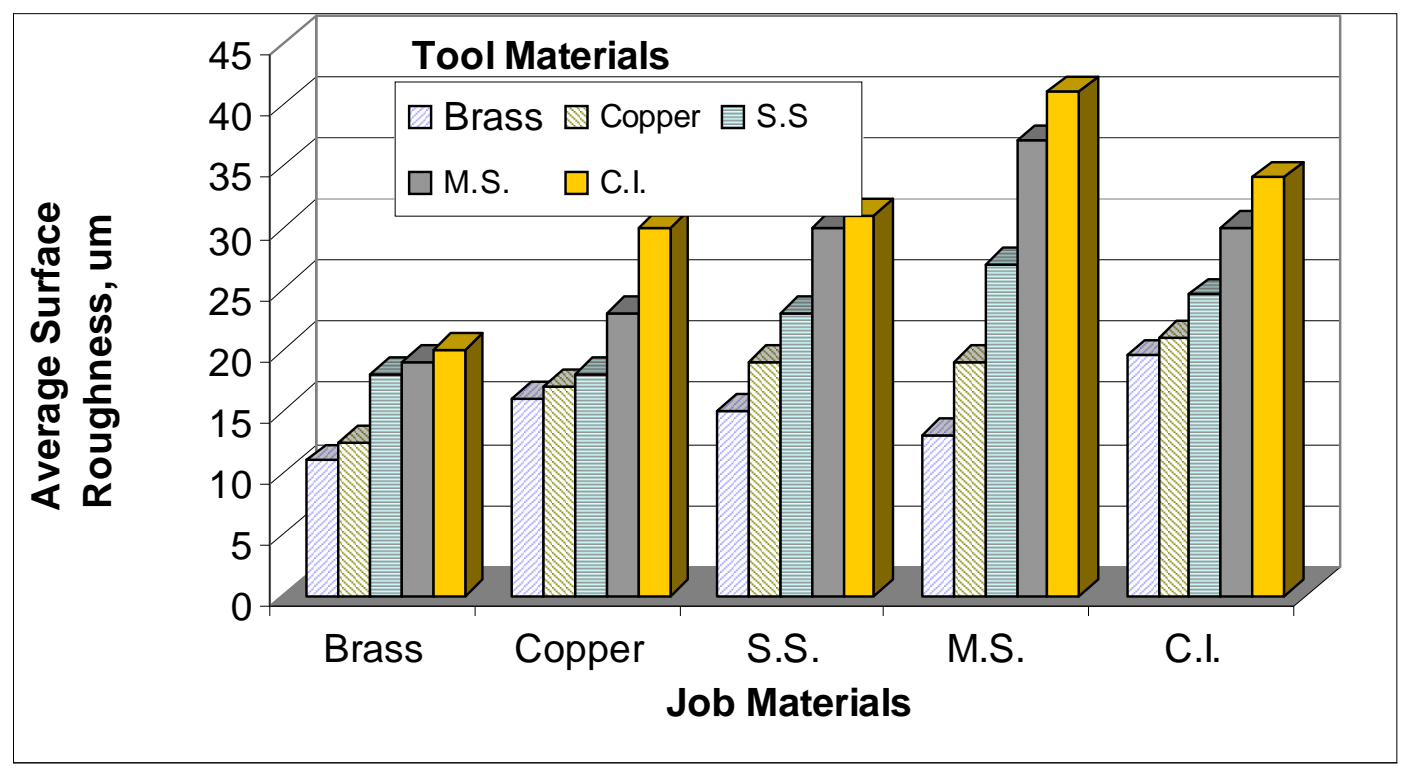

Fig. 5: Machined surface roughness attained for different work-tool material combinations.

\subsection{Surface Finish and Micro Size Cavities}

The surface roughness produced on the work piece, as shown in Figure 5, is higher in the cases of cast iron, mild steel and stainless steel and quite low in the cases of copper and brass. It is associated with the lower micro size cavities $(2-3 \mu \mathrm{m})$, formed on the machined surface by the brass and copper electrodes as compared to the cavities $(8-20 \mu \mathrm{m})$ formed by the other three materals. Larger cavity sizes in the cases of electrode materials with high melting point and low electrical conductivity may be related to higher amount of electrical energy that has to be accumulated for the electrical discharge to take place in these cases. On the other hand for electrodes with higher electrical conductivity electrical discharge takes place more frequently with lower accumulation of charge causing lower metal removal during each spark discharge. So the metal removal rate being high in the latter case, the cavity size remains small.

\subsection{Accuracy of the Machined Surfaces}

Figure 6 reveals the conical shape of the finished hole. This is due to higher duration of exposure of the side surface of the work piece to the sparking process. The tendency of debris to concentrate at the middle of the tool-work interface results in high bottom surface inaccuracy when the duration of machining is high. A convex shape is imparted to the bottom surface of the cavity specially when higher melting point materials like mild steel are machined with tools like brass having lower melting point (Fig. 6a).

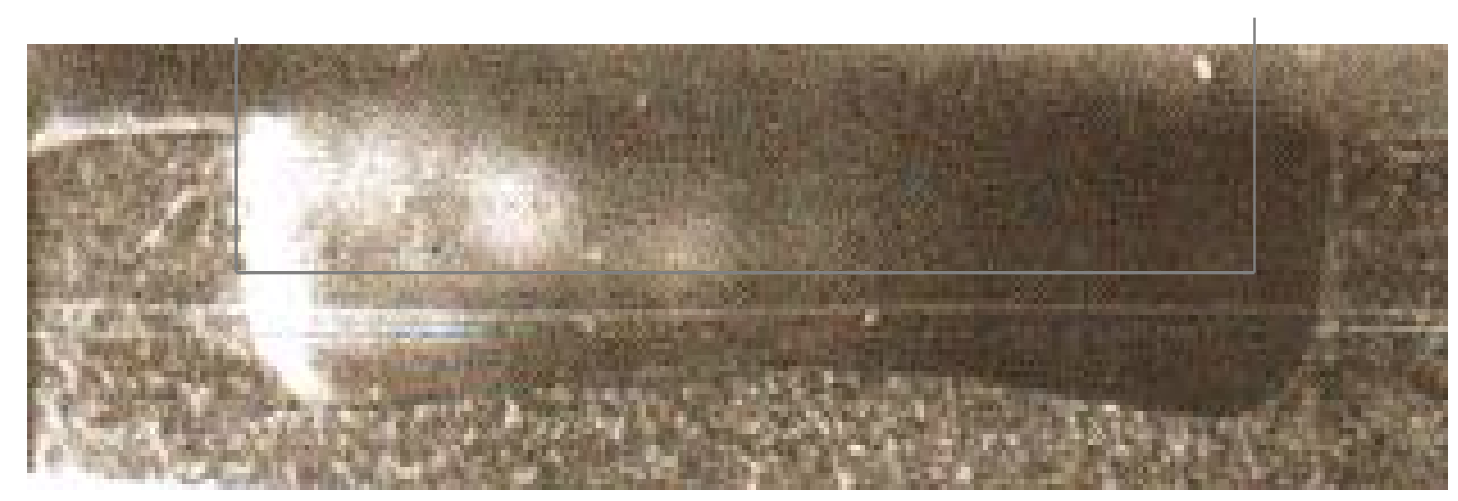

a): Tool: Brass 


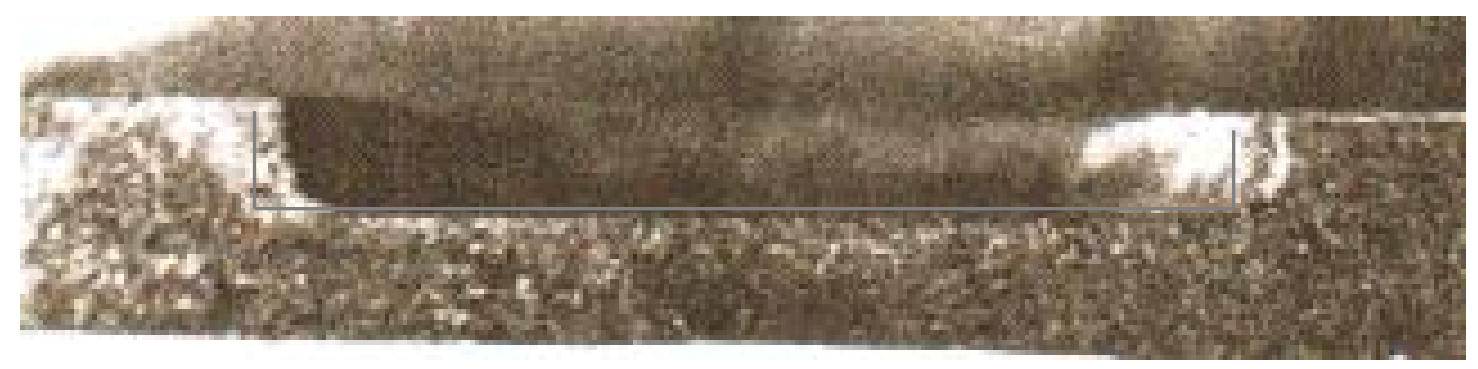

\section{b): Tool: Copper}

Fig. 6: The cross sectional view of the machined surface produced on mild steel by brass (a) and copper (b) electrodes.

This may be related to the fact that the bottom portion of the tool-work interface does not get effective circulation of the dielectric fluid and gets heated up. At an elevated temperature the low melting point electrode (brass) starts eroding out at a faster rate than the high melting point job material leading to a concave shape of the tool at its bottom surface and a corresponding convex shape to the mating job surface. But when high thermal conductivity material like copper is used as electrode material the out of flatness on the job bottom surface is almost absent because the the tool middle portion and the side surfaces are equally cooled. So in the case of copper electrode the bottom surface is almost flat and side taper is also low, which leads to the more accurate shape of cavity as compared to other electrodes.

\section{CONCLUSIONS}

From the experimental results and analysis the following conclusions may be drawn:

1. Material removal rate offered by brass electrode is the highest in the cases of machining brass, copper and mild steel and also maintains high values in the cases of stainless steel and cast iron. Copper electrodes offer higher metal removal rates than brass in the cases of the last two materials.

2. Tool wear per unit volume of job material removal (tool wear ratio) is the highest in the case of brass electrode and lowest in the case of copper electrode for all the investigated work piece materials. The remaining thre materials occupy intermediate positions with respect to tool wear ratio.

3. From the point of view of machined surface roughness the tool materials may be ranked in the ascending order as follows: brass, copper, stainless steel, mild steel and cast iron.

4. With regard to debris concentration and accuracy of machining copper is the best tool ad brass is the worst, specially for high melting point job materials.

5. For all the investigated job materials tool materials may be ranked with respect to the thickness of the recast layer formed on the machined surface, in the descending order as follows: copper, brass, stainless steel, mild steel and cast iron.

6. Brass electrode offering the highest rate of metal removal may be recommended for rough EDM machining of brass, copper and mild steel and copper electrode for rough machining of stainless steel and cast iron and also finish machining of all the investigated materials because of its minimum wear ratio and the highest accuracy of machining.

\section{REFERENCES:}

[1] S.L. S. Mandal,. and S. M. Raiskii, "Mechanism of Electro-Erosion of Metals", Izvestya Akademii Nauk SSSR, Moscow (USSR), Vol.13, pp.549-565, 1949.

[2] V.P Aleksandrov, "Residual Stresses and Long Term Fatigue Strength of Heat Resistant Materials after Electro-Spark Machining", Electro Spark Machining of Metals, Vol. 3, 1958, Consultants' Bureau, Newyork, 1958.

[3] M.M. Barash, "Effects of EDM on the Surface Properties of Tool \& Die Steels", Metals Eng. Quart, ASME, pp.48-51, 1965.

[4] K. P. Rajurka and S. R. Nooka, "Surface Finish of EDM Machine Components", Int. Conf. on Advanced Manufacturing Technology, Johor, Malaysia, 29-30, 1994.

[5] P. K Madan and R. Sagar, "The Electrical Discharge Machining of 60611/Sicp Composites", Int. Conf. on Advanced Manufacturing Technology, Johor, Malaysia, pp.163-171, 29-30, 1994.

\section{NOMENCLATURE}

ITS Intelligent Transportation Systems

GSM Global System for Mobile Communication

DRGS Dynamic Route Guidance System

GPS Global Positioning Systems

BS Base Station

PLMN Public Land Mobile Network

TA Timing Advance 
AB Access Burst

GLP Geographical Location Parameter
RSA Relative Signal Arrival

6. BIOGRAPHY 